\title{
ANGIOSARCOMA OF BONE- A RARE ENTITY
}

Abdul Wahid Ayubi, Nabaneet Majumder, P. V. Purohit, D. G. Paricharak, Seema S. More

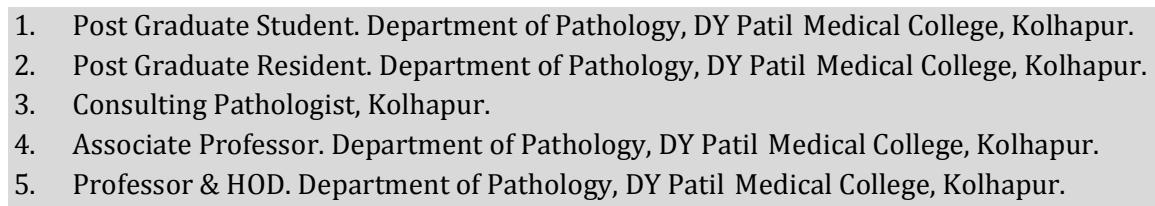

\section{CORRESPONDING AUTHOR:}

Abdul Wahid Ayubi,

Post Graduate Resident,

Department of Pathology,

D Y Patil Medical College, Kolhapur-416006.

E-mail: dr.abdulwahidayubi@gmail.com

Ph: 00917798703586.

ABSTRACT: Angiosarcoma is rare and constitutes $<1 \%$ of all malignant bone tumours. A seventy two year male presented with pain and soft tissue swelling around L4 vertebral body compressing nerve root. An uncomplicated biopsy of lesion was performed and a initial diagnosis of angiosarcoma was considered, further confirmed by immunohistochemistry. We here in report a rare case of angiosarcoma of bone with brief review of literature.

KEY WORDS- Bone, Angiosarcoma, Tumour, CD34 positivity

INTRODUCTION: Angiosarcoma is very rare and constitutes less than $1 \%$ of all malignant bone tumours. It shows wide range of age distribution from second to eighth decade. Males and females are almost equally affected. It shows involvement of bones of the extremity and the axial skeleton, mainly the spine.[1] It is most commonly associated with pain or, occasionally swelling.[2] Angiosarcomas are most commonly seen in soft tissue and are very rare in bones. We here report one such rare case of Angiosarcoma of Bone in a seventy two year male patient.

CASE REPORT: A 72 years male presented with pain and soft tissue swelling around L4 vertebral body compressing nerve root. X-ray showed lytic lesion in L-4 vertebral body. Biopsy revealed bony spicules with tumour showing intercommunicating blood vessels lined by atypical cells. Cells were pleomorphic with vesicular nuclei and prominent nucleoli. Bizarre tumour cells, multinucleated giant cells and abnormal mitotic figures were noted along with extensive areas of hemorrhages and necrosis. Immunohistochemistry showed CD34 positivity, which confirmed vascular origin of the tumour, and a diagnosis of primary angiosarcoma of bone was made. Surgical resection of the tumour was done in our case followed by chemotherapy. Eventually patient died after few weeks of treatment.

DISCUSSION: Angiosarcoma arises from the vascular endothelium and commonly occurs in soft tissues and skin. In 1925 Codman, in defining the nomenclature used by The Registry of Bone Sarcoma, believed that the term angiosarcoma in reality referred to vascular and telangiectatic forms of osteogenic sarcoma and as of that time, in his opinion, no true 
definition or example of a malignant vascular tumor of bone existed. In 1936, Robinson and Castleman, in reporting a case, put forth the concept of a benign hemangioma of bone giving rise to metastatic lesions which were microscopically malignant hemangiomas or true hemangiosarcomas. Again in the same year, however, Freilich recorded his criteria for angiosarcoma in the report of a case with a primary lesion in the right scapula with metastases to lung, spleen and liver. $\mathrm{He}$ felt the term should be used for cellular angiomas in which the unit is the vessel and not the endothelial cell and in which the neoplastic tissue reveals distinctive vasoformative tendencies. In 1942 Thomas classified vascular tumors as endotheliomas accompanied by definitive vasoformative tendencies with endothelial proliferation and new blood vessel formation. [3]

Primary angiosarcoma of bone is very rare and accounts for less than $1 \%$ of malignant bone tumour. [4] It shows involvement of long bones of the extremity and the axial skeleton, mainly the spine, and is most commonly associated with pain or, occasionally swelling. $\left.{ }^{[1,2}\right]$ Radiation associated angiosarcoma developing in unusual sites such as spleen, small bowel, urinary bladder and prostate have also been identified. [5]

Radiologically, it is an osteolytic tumour. The lesions are usually described as punched out areas of rarefaction or sharply circumscribed areas of destruction varying in size from a few millimeter to 2 to $3 \mathrm{~cm}$ in diameter. [3]

Histology reveals tumour composed of anastomosing vascular spaces lined by malignant cells. Inflammatory cells, especially eosinophils, may be prominent. In some angiosarcomas, the endothelial cells are cuboidal and have abundant pink hyaline cytoplasm and vesicular nuclei with a single prominent nucleolus, imparting an epithelioid appearance. This change may be present focally or occur throughout the lesion and is termed as epithelioid angiosarcoma. Several studies have used a histologic grading system for angiosarcoma. In grade-1 angiosarcoma, the vasoformation is obvious and the endothelial cells show minimal atypia. In grade- 2 lesions, the tumour is still easily recognizable as vasoformative and the endothelial cells have moderate atypia. Grade- 3 angiosarcoma is characterized by marked cytologic atypia and the tumour cells are so crowded together that the vasoformative features may not be apparent. Epithelioid angiosarcoma are always high grade. [2] The differential diagnosis of Angiosarcoma of bone includes Osteogenic sarcoma, Metastatic carcinoma. [5] Immunohistochemistry shows positivity for CD31, CD34 by tumour cells . ${ }^{[2,4]}$

Our case presented with pain and soft tissue swelling around L-4 vertebral body which on X ray showed a lytic lesion. Surgical resection of the mass was done which on light microscopy showed a tumour composed of intercommunicating vascular channels lined by atypical endothelial cells and there was no new bone formation, thus osteogenic sarcoma was ruled out. However, another differential of metastatic carcinoma especially renal cell carcinoma was also considered which was ruled out on the basis of intercommunicating vascular channels and absence of clear cells. Furthermore, the tumour cells also showed CD34 positivity on immunohistochemistry, thus confirming the diagnosis in our case.

Surgical resection is the treatment of choice in case of solitary lesion. However radiotherapy is indicated in cases of multicentric disease. [2] Hypervascularity of the lesion is another determinant and presurgical embolization can be used to make procedures safer. It is generally accepted that angiosarcomas have an aggressive course with poor 
prognosis. ${ }^{[6,7]}$ The survival differed depending on locations, and ranged from 1 year to 20 years with an average of 7.3 years. [8]

CONCLUSION: Angiosarcoma of bone is an extremely rare malignant neoplasm, however more emphasis should be given in early diagnosis of the disease with the help of clinicopathological and radiological studies so as to plan appropriate management of the disease.

\section{REFERENCES:}

1. Christopher DMF, Unni KK, Fredrik M. Pathology and genetics of tumours of soft tissue and bone. Lyon: WHO; 2002: 224-369

2. Unni KK, Inward CY, Bridge JA, Kindblom LG, Wold LE. Atlas of tumour pathology, $4^{\text {th }}$ series, fascicle 2.Tumors of the Bone and Joints. Washington DC: AFIP; 2005

3. John HC, Robert D, Carl N. Angiosarcoma of Bone: A Review of the Literature and Presentation of a Case. Annals of surgery 1956 July;144(1):107-117

4. Kudva R, Perveen S, Janardhana A. Primary epithelioidangiosarcoma of bone: A case report with immunohistochemical study. Indian J PatholMicrobiol 2010;53:811-813

5. Mittal et al. Post-irradiation angiosarcoma of bone. J Cancer Res 2007;3(2): 96-99

6. Khan S et al. Primary calvarial angiosarcoma: A case report and review of the literature. Surg Neurol Int. 2012; 3: 134.

7. Verbeke SLJ, Bovee JVMG. Primary vascular tumors of bone: a spectrum of entities? Int J Clin Exp Pathol 2011;4(6):541-551

8. Terada T. Angiosarcoma of the mandibular gingiva. Int J Clin Exp Pathol. 2011; 4(8): 791-793 

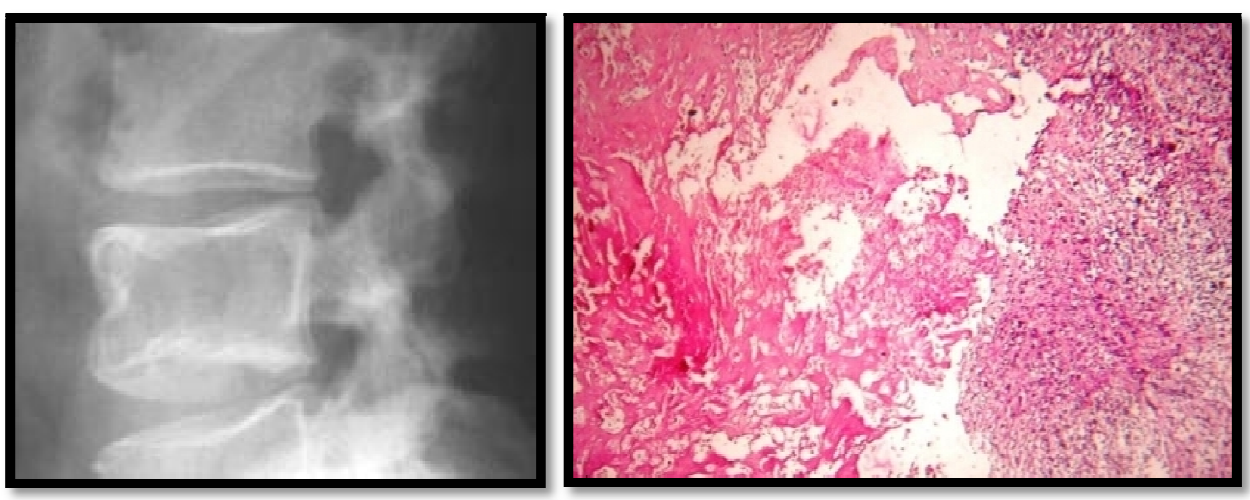

Figure 1-X-ray shows lytic lesion in $\mathrm{L}-4$ vertebra

Figure 2- Microphotograph shows bony tissue with Tumor
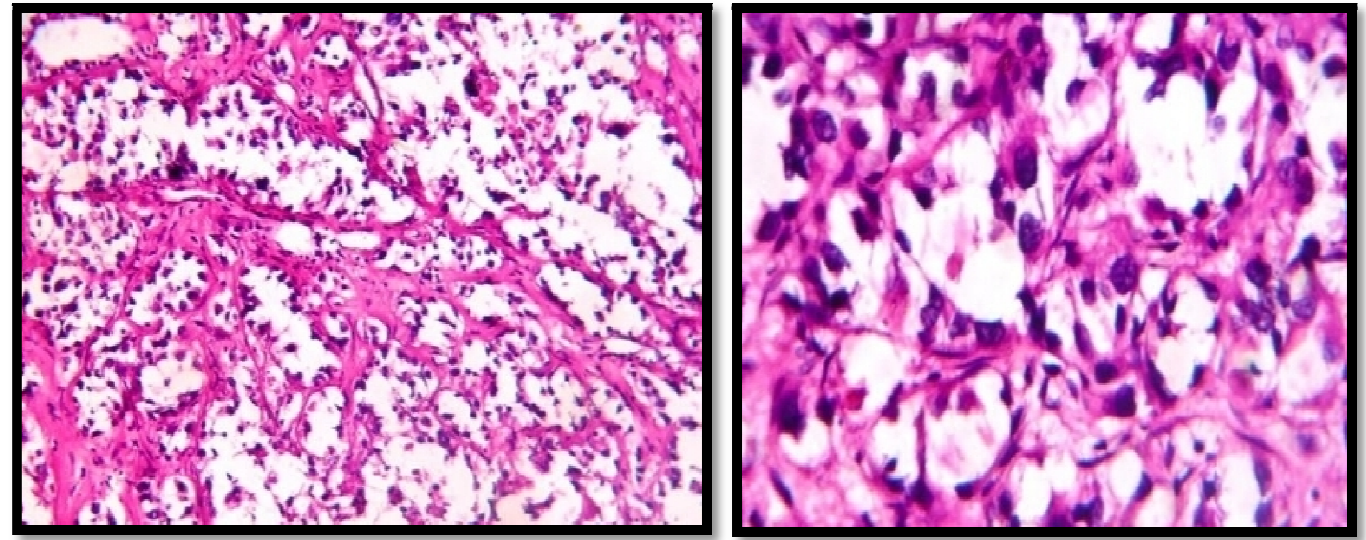

Figure 3- Microphotograph shows tumour

Figure 4- Microphotograph shows

forming vascular channels,lined by atypical

tumour forming vascular channels,lined endothelial cells (low power view)

by atypical endothelial cells (high power view)
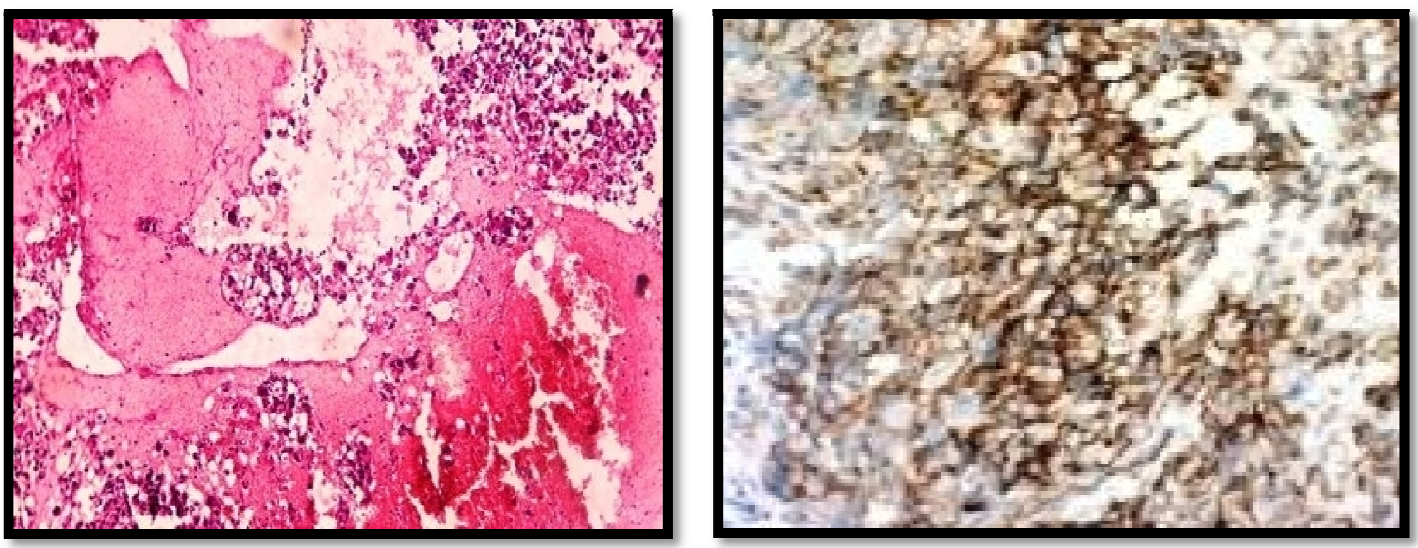

Figure 5- Microphotograph shows

Figure 6- Microphotograph shows CD 34 extensive areas of haemorrhage and necrosis positivity of tumour cells by immunohistochemistry 